\title{
Trajectories of life satisfaction and the financial situation in the transition to adulthood
}

\author{
Mette Ranta \\ Department of Psychology, University of Jyväskylä \\ mette.ranta@helsinki.fi \\ Angela Chow \\ University of Alberta, Edmonton \\ Katariina Salmela-Aro \\ Department of Psychology, University of Jyväskylä
}

(Received July 2012 Revised December 2012)

\section{Abstract}

The aims of this study were (1) to investigate young adults' life satisfaction changes during the transition to adulthood, (2) to identify possible life satisfaction developmental trajectories during the transition, and (3) to examine how individuals' agency and personal financial situations are related to the identified life satisfaction trajectories in the contexts of life-span and life course theories of development. The present study is part of the longitudinal Finnish Educational Transitions (FinEdu) study, in which a total of 372 (278 female and 94 male) young adults filled in questionnaires at four measurement points, that is, twice before (at 18 and 19 years of age) and twice after (at 20 and 22 years of age) the transition from upper secondary high school to tertiary education and/or employment. Growth Mixture Modelling revealed five trajectories of life satisfaction: low-stable (8\%), moderate-stable (41\%), high-stable (27\%), moderateincreasing (17\%), and high-decreasing (7\%). The vast majority (76\%) of young adults had a stable life satisfaction trajectory throughout the transition. High levels of achievement approach strategies at age 19 were somewhat related to high-decreasing and highstable life satisfaction trajectories. In turn, those using achievement avoidance strategies at age 19 were more likely to have low-stable or moderately-increasing life satisfaction trajectories. Positive life satisfaction trajectories were related to being in a positive financial situation at age 22. The two largest trajectories indicated better objective and subjective financial situations than did the other trajectories.

Keywords: young adulthood, life satisfaction, agency, developmental trajectories, longitudinal study, financial situation, person-oriented approach, Growth Mixture Modelling

\section{Introduction}

Financial situation and employment have been seen as some of the most important correlates of life satisfaction and sources of self-confidence, life management and capability in young adulthood (Cunnien, MartinRogers, \& Mortimer, 2009). However, the diverse transitions and individual changes taking place in this life course phase may alter both the development of life satisfaction as well as the personal financial situation. Additionally, macro-economic changes in society, such as during an economic crisis, may lead to changes in mental health due to perceived economic pressure (Stein et al., 2011). Both of these reasons highlight the importance of examining individuals' life satisfaction in relation to their financial situation. Although a large body of research has been conducted on young adults' and adolescents' financial situation, with topics including consumer 
behaviour motivation and purchasing power (e.g., Noble, Haytko, \& Phillips, 2008), disposable income and parental financial support (e.g., West, Sweeting, Young, \& Robins, 2006), relatively less research has examined the role of individuals' financial situation in this crucial and demanding life course phase from late adolescence to early adulthood in relation to their life satisfaction.

As societies prosper, differences in life satisfaction are less frequently due to differences in income. High life satisfaction does, however, often have positive outcomes, including economic ones relating to higher income and better job performance, rather than the other way around (Diener \& Seligman, 2004). In turn, financial wellbeing, that is, having a stable economic situation with little debt and greater financial satisfaction, does seem to positively affect overall life satisfaction in this particular life course phase of young adulthood (e.g., Shim, Xiao, Barber, \& Lyons, 2009). However, regarding change in overall life satisfaction, only a few studies have focused on its development or heterogeneity across an educational transition, which often involves distinct changes that are either positive or negative and which also might change the related quality of life satisfaction (e.g., Salmela-Aro \& Tuominen-Soini, 2010; Salmela-Aro \& Tynkkynen, 2010) and wellbeing (e.g., Haase, Heckhausen, \& Silbereisen, 2012).

In this study, we examine - through longitudinal research - whether young adults' life satisfaction changes, and what kinds of life satisfaction trajectories can be found across the challenging developmental transition in young adulthood, after upper secondary high school, into tertiary education and/or employment, between ages 18 and 22. Secondly, we examine young adults' financial situation and agency in relation to their life satisfaction.

\section{Financial challenges and life satisfaction}

The phase of young adulthood is, according to Rindfuss (1991), demographically "dense" in that a great number of changes and demographic events occur simultaneously, such as moving out of the childhood home and taking part in further education and/or employment. These demographic markers of the transition to adulthood are also linked to financial independence (Lee \& Mortimer, 2009). Graduation and the beginning of employment foster financial independence, which may affect other markers of adulthood and life course events relating to education, employment, moving out of the childhood home and establishing a family (Billari, 2001; Lee \& Mortimer, 2009; Modell, Furstenberg, \& Hershberg, 1976).

These transitionary life events which initiate long-term changes and a reorganisation of one's life (Cowan, 1991) may have a profound effect on overall life satisfaction, either through stimulated personal growth, or dysfunction and stress (Perren, Keller, Passardi, \& Scholz, 2010). Success in dealing with life course transitions and the relatively early completion of adult transitions in the education and work domains, for example, as evidenced by various transitional pathways, may contribute to young adults' subsequent life satisfaction and well-being (Räikkönen, Kokko, Chen, \& Pulkkinen, 2012; Salmela-Aro, Ek, Taanila, \& Chen, 2012; Schulenberg, Sameroff, \& Cicchetti, 2004). Instability in life satisfaction and its relation to contextual circumstances have also been witnessed in a study by Lucas and Donnellan (2007). Evidently, some young adults find difficulty in adapting to the changes and challenges taking place during the major life course phase of the transition to adulthood, and the inherent instability of the transition may make this life course phase confusing and unsettling, characterised by individuals' ill-health and unhappiness (Hendry \& Kloep, 2007a), anxiety (Hendry \& Kloep, 2007b), maladaptive functioning leading to precarious trajectories (Côté \& Bynner, 2008), and negative self-esteem and depressive symptoms (Luyckx, De Witte, \& Goossens 2011). On the other hand, on the basis that the majority of young adults face no severe problems in their youth, many other researchers see late adolescence as a prime time for a wide range of opportunities (Eccles et al., 1993; Graber \& Brooks-Gunn, 1996; Powers, Hauser, \& Kilner, 1989) and the transition also as a turning point for positive personality trait change, as in a study by Lüdtke, Roberts, Trautwein and Nagy (2011) where high school (upper secondary) students were found to be "more agreeable, conscientious and emotionally stable" after the transition from high school to college.

Success in developmental tasks, such as in forming stable employment careers in this life course phase, demands active behaviour and agentic strivings from young adults (Vuolo, Staff \& Mortimer, 2012). According to the life-span model 
of motivation (Heckhausen, Wrosch, \& Schulz, 2010; Nurmi, 2004; Salmela-Aro, 2009), individuals follow and regulate their personal developmental paths by choice and selection. This is related to adapting and pursuing developmental and personal goals that reflect changes in life course opportunities. This agentic process does not, however, occur independently from changing social contexts: social structure, culture and historical life context (Freund \& Riediger, 2006; Salmela-Aro \& Little, 2007). The life-span model of motivation is guided by the sociological life course approach to human development (Bronfenbrenner, 1979; Elder, 1998a), which states that human development is shaped by a set of interacting spheres of influence and principles, not only including individual agency but also the timing of events, linked lives and the embeddedness of development in its sociohistorical context.

During a transition period, individuals need to negotiate their lives according to the constraints and opportunities imposed on individual agency (Elder, 1998a). As regards agency, the focus is on the individuals' ability and power to act in a way that is different to what has been spelled out for her or him (Giddens, 1991). During the transition from school to work, personality and psychological orientations fostering achievement and indicating agentic striving, may also help young adults to cope with economic turbulence and the current structural changes in working life, uncertain labour markets and tougher economic conditions that may challenge young adults' passage into adulthood (Mortimer \& Larson, 2002), life management and school-to-work transitions (Furlong \& Cartmel, 2007; Marks, 2005). An unfortunate life event, such as unemployment, within an important life course transition, may have an impact on the individual's life satisfaction. On the other hand, individuals with better psychological readiness may be more capable of meeting the challenges of such a concurrent life event and life course transition. In this study, agency is operationalised in terms of achievement strategies, to assess how young adults approach challenging life situations. These strategies are usually operationalised as being either approach optimistic (functional) or avoidant (dysfunctional) (Eronen, Nurmi, \& Salmela-Aro, 1997; Nurmi, Aunola, SalmelaAro, \& Lindroos, 2003).

Prior studies (e.g., Roberts, Osadchaya, Dsuzev, Gorodyanenko, \& Tholen, 2003) have shown that economic reforms and tougher labour market conditions have not influenced young adults' life course transitions relating to housing and family formation as much as new individual lifestyle options and choices. Young adults seem to be able to accommodate their consumption to their individual income level as they conduct individual comparisons to others (Roberts, Osadchaya, Dsuzev, Gorodyanenko, \& Tholen, 2003). A recent study by Stein et al. (2011) showed that in accounting for variation in levels of psychological distress among 21 year-old college students, greater personal financial strain of the economic crisis - specifically on personal, individual lifestyles - was much more salient compared to felt family economic pressure, as seen in a study by Conger and colleagues (1999). Nevertheless, in the prolonged transition to adulthood, young adults are increasingly financially dependent on their parents (Johnson and Benson, 2012) in times of youth unemployment, this financial dependency can have a profound risk on self-efficacy (Mortimer, 2012). Family social class background and income do need to be considered as factors affecting the possibilities for independence and options for deciding on taking a break from developmental tasks in young adulthood, as wealthy young middleclass adults with supportive parents tend to have an advantage in this regard (Furlong \& Cartmel, 2007).

Perren et al. (2010) have noted that studying changes in well-being over time requires timeconsuming longitudinal study designs, with several measurement points that start before the transition. In the present study, life satisfaction development is viewed across the transition to adulthood, and more specifically, during the transition from upper secondary high school to employment and/or further education. The study has a longitudinal perspective, reflecting the recent emphasis on the need for such longitudinal multiwave studies, rather than cross-sectional ones, in order to understand different developmental processes (Diener \& Seligman, 2002). Another limitation concerning earlier studies on life satisfaction among young adults, is their focus on the developmental course of life satisfaction solely at the mean level (e.g., Costello, Swendsen, Rose, \& Dierker, 2008), not addressing the possibility that individual trajectories could be different. In line with Salmela-Aro and Tynkkynen (2010), a possible approach is to use person-oriented (Bergman, 
Magnusson, \& El-Khouri, 2003) trajectory analysis (Nagin, 1999; Nagin \& Land, 1993; Nagin \& Tremblay, 1999), or Growth Mixture Modelling (GMM; Muthén, 2004; Muthén \& Muthén, 2000; Muthén \& Shedden, 1999), which may be more fruitful methods for examining human development.

\section{Transition to adulthood in Finland}

The focus of this study is on young adults' (aged 18 to 22) transition to adulthood, from completing upper secondary high school education to beginning their tertiary education and/or employment in Finland. In addition to the educational transition taking place, young adults gain legal adult status in Finland on becoming 18 years of age, which includes the right to marriage, leaving church membership, buying mild alcoholic drinks and cigarettes, obtaining a driving licence, and the right to vote; and for men, the responsibility to serve in the army or civil service.

The welfare regulations, social policies and legislation of the Scandinavian countries emphasise societal universal support systems and individual rights to state-granted economic incentives and benefits (Esping-Andersen, 1990; Furlong \& Cartmel, 2007). The universal support of the Nordic welfare state provides a good example of how the socio-economic and political context and its structures interact with personal aspirations and accomplishments regarding developmental tasks. Buchmann and Kriesi (2011) argue that this sociopolitical welfare system is related to the observed patterns in early home-leaving and non-traditional family formation. Such regulations and policies may reduce the negative impact that global and national economic uncertainty has on individuals and their life course transitions (see also Ranta, Punamäki, Tolvanen, \& Salmela-Aro, 2012). As a result, structural changes in the economy may not have as dramatic an impact on young adults' economic situation in Finland as in countries without welfare programs (Blossfield, Klijzing, Mills, \& Kurz, 2005).

The impact of governmental financial aid is also strongly evident in educational patterns. Education in Finland, at all levels, is state-provided and tuition is free of charge. This, as well as the fact that students are provided with state benefits, supports equal opportunities for all young adults irrespective of family background. Students attending upper secondary school, a vocational institute or higher education institute, receive government financial aid, which consists of a study grant, a housing supplement and a government guarantee of a student loan. Study grants and housing supplements are cash benefits from the state and they do not need to be paid back. The student loan is a normal bank loan granted by all Finnish banks upon application (EUROSTUDENT, 2005-2008). Before the recession of the national economy in the early 90s, the student financial aid system was mainly based on subsidised student loans. The system was reformed in 1992 with the abolition of government loans as subsidies for students, but the study grant amount was more than doubled. This resulted in the unpopularity of student loans and shifted students' interest from loan-based to employment-based income (Häkkinen, 2004; Häkkinen \& Uusitalo, 2003). Consequently, according to recent Statistics Finland data (2011a), more than half (55\%) of Finland's students are employed whilst studying.

The participants of this study were students who attended upper secondary high school, which approximately $50 \%$ of Finnish young adults attend (Official Statistics of Finland, 2011). After a three- to four-year period in upper secondary school, graduates may (among other options) apply for tertiary education and/or enter working life. A special problem of the Finnish educational system is the issue of late entry into higher education after upper secondary school (Ministry of Education and Culture, 2005). Because competition for admission to higher education is extremely tough, only roughly half of those completing the final matriculation examination move into higher education in the same year as their earlier graduation from secondary level, as is also the case regarding the transition from secondary education to employment (Statistics Finland, 2009, 2010b).

Even though young Finnish adults move out of their childhood home relatively early compared to others in the European Union member states, there is a significant gender gap present. In the European Union countries in 2008 , about $76 \%$ of young adults aged 18-24 still lived with their parents in their childhood home (71\% of women, $81.5 \%$ of men). Finland and Lithuania shared the second-widest gender gap for this measure (21 percentage points (pp)), below Bulgaria's gender gap of $23 \mathrm{pp}$ (Eurostat Statistics, 2010). Leaving the childhood home is often related to financial security as factors involved include receiving financial support from 
parents, labour market conditions, and the cost of housing (Eurostat, 2009). In the European Union in general, $44 \%$ of $15-30$ year olds consider that young adults cannot afford to leave their parental home and $28 \%$ agree that not enough affordable housing is available. In Finland, however, it is fairly easy to rent an apartment and the housing supplement of the student financial aid package promotes early transitions.

\section{Aims and hypotheses}

The overall aim of this longitudinal study was to bring forward comprehensive information concerning the role of economic determinants acting on life satisfaction during the transition to adulthood, by using a person-oriented approach. Specifically, our research questions were:

(1) How does young adults' life satisfaction change during the transition to adulthood?

(2) What are the possible types of life satisfaction trajectories emerging during the transition to adulthood? Do these trajectories differ according to gender or family socioeconomic status, parental financial support, living situation or life situation?

(3) How are achievement strategies (i.e., agency), associated with the identified life satisfaction trajectories?

(4) How is the financial situation of young adults', during the transition to adulthood, associated with the identified life satisfaction trajectories?

Based on previous studies, we tested the following hypotheses: $(\mathrm{H} 1)$ life satisfaction remains fairly stable during the transition to adulthood for the majority of young adults (Eccles et al., 1993; Graber \& Brooks-Gunn, 1996; Powers, Hauser, \& Kilner, 1989); (H2) due to differences between young adults, and as seen in the studies by Perren et al. (2010) and Salmela-Aro and Tynkkynen (2010) concerning normative educational transitions, different trajectories of life satisfaction can be found as some individuals experience an increase and some a decrease in life satisfaction, while most do nevertheless encounter stability; (H3) active agency and the use of achievement approach strategies (see Perren et al., 2010; Eronen, 2000) are significantly associated with life satisfaction; and (H4) a positive financial situation is related to high life satisfaction (Ervasti \& Venetoklis, 2010; Jorgensen, Jamieson, \& Martin, 2010; Shim et al., 2009). As can already be identified from the theoretical introduction, our perspective on the transition to adulthood attempts to integrate the sociological life course transition approach with the psychological markers of agency, in examining life satisfaction development and the financial situation in the transition to adulthood.

\section{Method}

\section{Data}

The empirical data of the present study was taken from the ongoing longitudinal Finnish Educational Transitions (FinEdu) Studies, gathered using written self-report questionnaires addressed to all upper secondary high school students (6 schools, 28 classes) living in the same mid-sized Finnish city (population $=105,000$ ). During their transition to adulthood, participants filled in questionnaires for data collection twice in upper secondary school before the transition (in their second and third years, at 18 and 19 years of age, referred to as Time 1/2004 [T1] and Time 2/2005 [T2]), and twice after the transition (at 20 and 2223 years of age, referred to as Time 3/2006 [T3] and Time 4/2008-2009 [T4]), from upper secondary high school to the commencement of higher education and/or employment. At the first measurement point, 614 (response rate $80 \%$; 376 female and 237 male, 1 unreported), at the second measurement point 636 (83\%; 425 female and 211 male), at the third measurement point 449 (61\%; 327 female and 122 male), and at the fourth measurement point 422 (59\%; 287 female and 132 male, 3 unreported) young adults answered the questionnaire. Because the focus of our study is on the educational transition period, the measurement taken immediately after graduating from high school (upper secondary school) (i.e., T3) was of special interest. Therefore, only those respondents who provided responses to at least one item on life satisfaction at T3 were included in the final sample of the study ( $N=372 ; 278$ female [75\%] and 94 male [25\%]).

\section{Measures}

Life satisfaction was measured using the Satisfaction with Life Scale (SWLS) by Diener, Emmons, Larsen and Griffin (1985). Participants rated five items (for example, "I am satisfied with 
my life", and "The conditions of my life are excellent") on a 7-point Likert-type scale ranging from 1 (totally disagree) to 7 (totally agree). A mean score was calculated for all items. The Cronbach's alpha reliabilities ranged from .85 to .88 across the four measurement points, indicating a high level of internal consistency with respect to the life satisfaction variable.

Achievement strategies were assessed in relation to achievement approach and achievement avoidance strategies measured at $\mathrm{T} 1$ and $\mathrm{T} 4$ by four-item scales taken from the Strategy and Attribution Questionnaire (SAQ; Nurmi, SalmelaAro, \& Haavisto, 1995). Achievement approach strategies measured the extent to which people expect to succeed in a task and are not overly apprehensive of failure, e.g., "When I get ready to start a task, I am usually certain that I will succeed in it". Achievement avoidance strategies measured the extent to which people tend to behave in ways that prevent them from carrying out a task, e.g., "What often occurs is that I find something else to do when I have a difficult task in front of me". Responses were given on a scale from 1 (strongly disagree) to 7 (strongly agree). The Cronbach's alpha reliabilities at T1 were .81 for achievement approach and .82 for achievement avoidance.

Financial situation was measured by two questions with regard to participants' subjective and self-reported objective financial situation at Time 4 (T4). Participants' subjective financial situation was measured by examining perceived income sufficiency in terms of personal consumption habits, with a 5-point Likert scale ranging from 1 (poorly) to 5 (extremely well) corresponding to the question, "Do you think your income covers your expenses at the moment?" Participants' self-reported objective financial situation was measured with the question, "How much money do you have for use monthly?" The participants were asked to report the amount of their monthly income, including salary (EUR), financial support (e.g., student/housing financial aid from the state), support from parents and relatives, loans (including mortgage/study loans, consumer credit), and other types of income. In the analyses, these amounts were summed. The income distribution of the respondents varied. $44 \%$ of respondents received a salary $(M=518$ EUR monthly, $S D=520), 57 \%$ received financial support from the state $(M=405$ EUR monthly, $S D=119)$,
$42 \%$ received financial support from family or other relatives ( $M=99$ EUR monthly, $S D=105), 20 \%$ had a loan $(M=150$ EUR monthly, $S D=218)$, and $12 \%$ indicated receiving money from other sources $(M=$ 254 EUR monthly, $S D=662$ ). The relative contribution of these different sources to total income at age 22 was as follows: $40 \%$ was received as a salary, $41 \%$ as financial support from the state, $7 \%$ as financial support from family or other relatives, $5 \%$ as a loan, and $5 \%$ from other sources. These descriptive data are comparable to figures for the majority of young adults in Finland. As in most European Union countries, employment and one's own earnings are the main source of students' income, along with financial support from the state (Orr, Gwosć, \& Netz, 2011). Parental financial support was minor in comparison, as was the popularity of loans, as discussed earlier. The findings thus concur with the general trend in Finland of a shift in responsibility for financial security away from the parents and toward the state and the individuals themselves (Ranta et al., 2012).

\section{Background information}

Respondents' gender was asked at the initial measurement time (T1). Family socio-economic status (SES) was measured by asking the participants to report their parents' occupations. In cases where this information was not available at the initial measurement (T1), this data was used from T2. Answers were classified into five socioeconomic categories using a standard classification system (Statistics Finland, 1989). The five categories were: 1) not in employment, 2) self-employed, 3) blue-collar occupation, 4) lower white-collar occupation, and 5) higher white-collar occupation. Out of those who replied, the occupational distribution of participants' fathers was as follows: $7 \%$ were not in employment (students, retired or unemployed, all seen as having a low income), 13\% were self-employed, $25 \%$ worked in blue-collar occupations (e.g., construction workers, mechanics), $16 \%$ worked in lower white-collar occupations (e.g., secretaries, salespersons, nurses), and $39 \%$ worked in higher white-collar occupations (e.g., physicians, teachers, lawyers, managers). For mothers, the occupational distribution was as follows: $7 \%$ were not in employment, $6 \%$ were selfemployed, $13 \%$ worked in blue-collar occupations, $47 \%$ worked in lower white-collar occupations, and $27 \%$ worked in higher white-collar occupations. 
Applying the household reference person definition (HRP; Department for Commmunities and Local Government 2011; Statistics Finland 2011b), we have used the person with the highest occupation as a reference for family socio-economic status. In the case of self-employment, the occupation of the other parent was taken into account, except if the other parent was not in employment or the information was missing. As a result, the household socio-economic status was as follows: $2 \%$ not in employment, $5 \%$ self-employed, $11 \%$ blue-collar, $35 \%$ lower white-collar, and $47 \%$ higher whitecollar.

In terms of living situation, at the age of 22, most of the respondents had moved from their childhood homes into independent living: only $2 \%$ lived with their parent/s, $20 \%$ lived with a friend or roommate, $33 \%$ lived alone, $42 \%$ lived with a boyfriend/girlfriend or husband/wife, and $3 \%$ had some other living arrangement. In terms of life situation, the majority of participants were still studying at the age of 22 , mostly in university (34\%) or at a polytechnic institute (25\%). Many participants were in a life situation characterised by combining different tasks, as $42 \%$ were simultaneously studying and working.

\section{Attrition analyses}

As noted earlier, the final sample comprised those participants who provided responses to at least one item on life satisfaction at T3 $(n=372)$. A series of $t$-tests was conducted with respect to these 372 participants in order to compare their life satisfaction scores with those who participated at all measurement points $(n=200)$ and those with missing data at some measurement points $(n=$ 172). No significant differences were found. By using the missing data procedure (see next section for more details), we were able to supply data on all of the participants in the analyses.

With regard to gender, the majority $(64 \%)$ of participants in our entire sample of 733 respondents were female, which reflects the overall distribution of high school (upper secondary) students in Finland as $57 \%$ of these constituted women in 2009 (Statistics Finland, 2010a). The $t$ test showed a significant selection effect favouring female respondents, $t(400)=-3.96, p<.001$. This is a limitation of the study and will be discussed further in the Discussion section. However, a parallel $t$-test confirmed that there was no selection effect $[t(717)=-.06, p=.95, \mathrm{~ns}]$ in terms of family socio-economic status (see above).

\section{Analysis strategy}

Analyses were conducted in three phases. First, to answer our first research question on how life satisfaction changes during the transition to adulthood, Latent Growth Curve Modelling (LGCM; Duncan, Duncas \& Strycker, 2006; Muthén \& Muthén, 1998-2007) was conducted to estimate the average initial level and slope of life satisfaction among the participants.

The goodness-of-fit of the estimated LGCM was evaluated according to the following indicators: (1) $\chi^{2}$-test; (2) Comparative Fit Index (CFI; Bentler, $\underline{1990)}$ with a cut-off value of $\geq .95$; (3) Root Mean Square Error of Approximation (RMSEA; Steiger, $\underline{1990)}$ with a cut-off value of $\leq .08$; and (4) Standardized Root Mean Square Residual (SRMR; Hu \& Bentler, 1998) with a cut-off value of $\leq .09$.

To answer our second research question on whether different types of life satisfaction trajectories emerge during the transition to adulthood, the analyses of this longitudinal data set were extended into Growth Mixture Modelling (GMM; Muthén, 2001, 2004; Muthén \& Muthén, 2000; Muthén \& Shedden, Muthén \& Shedden,1999). GMM can be used to examine unobserved heterogeneity in the development of an outcome over time, by identifying homogeneous subpopulations that differ with respect to their developmental trajectories within the larger heterogeneous population. GMM is exploratory by nature, which means that there are no specific a priori assumptions regarding the number of latent classes to be found. Typically, in running GMM, a series of models are specified. The best-fitting model is then selected based on a list of criteria, including the goodness-of-fit indices and conceptual considerations. In this study, the following goodness-of-fit indices were used to evaluate the models: Akaise's Information Criteria (AIC), Bayesian Information Criteria (BIC) and Adjusted Bayesian Information Criteria (aBic) of the alternative models. Entropy values were also examined, with values close to 1 indicating a clear classification. Following Marsh, Lüdtke, Trautwein, and Morin (2009) and Bowen, Lee and Weller (2007), groups of $\geq 5 \%$ of the sample were considered the smallest to give an acceptable solution. Practical usefulness, theoretical justification and interpretability of the latent group 
solutions were also taken into consideration (see also Bauer \& Curran, 2003; Marsh et al., 2009; Muthén, 2003). The analyses were controlled for gender and SES.

Both LGCM and GMM analyses were conducted with the Mplus 5.0 statistical software programme (Muthén \& Muthén, 1998-2007), using the missingat-random (MAR) approach to missing data, which uses all of the available observations in the data set when estimating the parameters of the models. This model does not assign values for data that are missing but it uses all of the data that are available to estimate the model using the full information maximum likelihood ratio (MLR). Because the variables were skewed, the parameters of the LGCM and GMM analyses were estimated using the default MLR estimator (Muthén \& Muthén, 19982007).

Finally, to answer the third and fourth research questions, we used One-Way Analysis of Variance (ANOVA) to examine if the life satisfaction trajectory groups differed in terms of their achievement strategies and financial situation. Post hoc comparisons using the Games-Howell test were used to examine the differences between groups. Missing data was handled by applying listwise deletion in these ANOVA analyses.

\section{Results}

\section{Descriptive results}

The sample correlation matrix, scales, means $(M)$, standard deviations $(S D)$ and Cronbach $\alpha$ reliabilities for the key variables are shown in Table 1.

\section{Development of life satisfaction}

The first research question was concerned with the longitudinal change in young adults' life satisfaction during the transition to adulthood. To answer this question, we specified a Latent Growth Curve Model with a linear slope for change in life satisfaction across the four measurement points. The model fit the data well $\left[\chi^{2}=15.79(5), p<.01\right.$; $\mathrm{CFI}=.97 ; \mathrm{RMSEA}=.08 ; \mathrm{SRMR}=.06]$.

The intercept (i.e., initial level) of life satisfaction was statistically significant, but the linear slope was not [Intercept $M=4.90, S E=0.06$, $p<.001$; Slope $M=0.01, S E=0.02, p=n s]$. This indicated that, on average and as hypothesized (H1), there was no significant longitudinal change in life satisfaction across the four measurement points. Interestingly, the variances of both the intercept and the slope were significant (variances = $0.92, p<.001$ and 0.04(0.01), $p<.01$, respectively), indicating significant individual variances both in the initial levels and in the rate of change. Consequently, although the model showed no linear change in life satisfaction development on average, supporting our hypothesis $(\mathrm{H} 2)$, there was significant heterogeneity among individuals. This indicated that a single latent trajectory was not able to sufficiently capture the heterogeneity of the changes in life satisfaction. Therefore, we aimed to identify different classes of life satisfaction trajectories in the next phase of analysis. 
Table 1. Correlations, scales, means, standard deviations, and reliabilities for the variables used

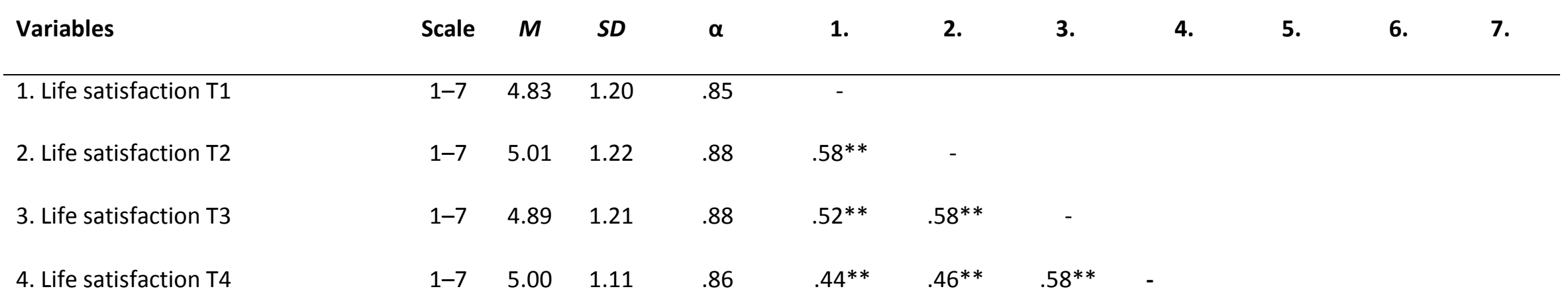

\section{Financial situation}

\begin{tabular}{|c|c|c|c|c|c|c|c|c|c|c|c|}
\hline 5. Objective financial situation T4 & - & 834 & 498 & - & .13 & .11 & $.15^{*}$ & .04 & - & & \\
\hline 6. Subjective financial situation $\mathrm{T} 4$ & $1-5$ & 3.27 & 1.19 & - & $.16^{*}$ & $.19 * *$ & $.20 * *$ & $.19 * *$ & $.45^{* *}$ & - & \\
\hline \multicolumn{12}{|l|}{ Achievement strategies } \\
\hline 7. Achievement approach T1 & $1-7$ & 4.96 & .88 & - & $.40 * *$ & $.51^{* *}$ & $.36^{* *}$ & $.23^{* *}$ & $.16^{*}$ & .10 & - \\
\hline 8. Achievement avoidance T1 & $1-7$ & 3.58 & 1.27 & - & $-.23 * *$ & $-.29 * *$ & $-.20 * *$ & $-.19 * *$ & -.07 & -.07 & $-.42 * *$ \\
\hline
\end{tabular}

$T 1=$ Time $1 / 2004$, at 18 years; $T 2=$ Time 2/2005, at 19 years; $T 3=$ Time 3/2006, at 20 years; T4 = Time 4/2008-2009, at 22-23 years of age 


\section{Identifying life satisfaction trajectories}

GMM procedures were employed to identify the different life satisfaction trajectories. Two- to six-class models were tested. Similar to the LGCM procedures, the loadings for T1 (age 18), T2 (age 19), T3 (age 20) and T4 (age 22) were fixed to 0, 1, 2, and 4. Table 2 shows the fit indices and class frequencies for different growth mixture solutions. All of the entropy values were acceptable, ranging from .677 to .779 . The sixclass solution was considered unsatisfactory because it included a trajectory with a very small class (2\%). Both the $\mathrm{aBIC}$ and AIC favoured the five-class model over the four-class model. The BIC index of the four-class solution was lowest (BIC $=3,735.69$ ), but it did not differ substantially from that of the five-class solution ( $B I C=3,736.84)$. As a result, the five-class model was considered to be optimal.

To further confirm whether this five-class model with a linear slope fit the data better than an alternative model with a nonlinear slope, we ran a model with loadings for $\mathrm{T} 1, \mathrm{~T} 2, \mathrm{~T} 3$ and $\mathrm{T} 4$ as being respectively: $0,1,2$, and $*$. The loading for T4 was set as free, allowing non-linear change. The results for this alternative model were: $\mathrm{BIC}=3,739.84, \mathrm{aBIC}=$ $3,679.56$, and $A I C=3,665.38$. Compared to the fiveclass model with a linear slope $(\mathrm{BIC}=3,736.84, \mathrm{aBIC}=$ $3,679.73$, and $A I C=3,666.30$ ), this alternative model did not fit the data better. Moreover, this alternative model included a class consisting of only $1 \%$ of the sample, which was unsatisfactory.

Finally, we conducted a quadratic model with loadings for T1, T2, T3 and T4 as 0, 1, 4 and 16, respectively. The results of this quadratic alternative were: $\mathrm{BIC}=3,737.15, \mathrm{aBIC}=3,708.59$, and $\mathrm{AIC}=$ 3,701.88. This alternative model did not fit the data better, and further confirmed the five-class model with a linear slope as optimal. Having tested these alternative models, we concluded that the five-class model with a linear slope yielded the best fit. The subsequent analyses were based on this five-class model.

\section{Table 2. Fit indices and class frequencies based on estimated posterior probabilities for growthmixture models of life satisfaction with different numbers of latent trajectory groups}

\begin{tabular}{|c|c|c|c|c|c|}
\hline Number of groups & BIC & $\mathrm{aBIC}$ & AIC & Entropy & $\begin{array}{l}\text { Number of } \\
\text { estimated } \\
\text { parameters }\end{array}$ \\
\hline 1 & $4,133.52$ & 4,114.49 & $4,110.01$ & - & 6 \\
\hline $2\left(n_{1}=27 \%, n_{2}=73 \%\right)$ & $3,841.17$ & $3,812.61$ & $3,805.90$ & .779 & 9 \\
\hline $3\left(n_{1}=47 \%, n_{2}=44 \%, n_{3}=9 \%\right)$ & $3,743.47$ & $3,705.40$ & $3,696.45$ & .752 & 12 \\
\hline $4\left(n_{1}=14 \%, n_{2}=33 \%, n_{3}=8 \%, n_{4}=45 \%\right)$ & $3,735.69$ & $3,688.10$ & $3,676.91$ & .697 & 15 \\
\hline $5\left(n_{1}=7 \%, n_{2}=27 \%, n_{3}=17 \%, n_{4}=8 \%, n_{5}=41 \%\right)$ & $3,736.84$ & $3,679.73$ & $3,666.30$ & .677 & 18 \\
\hline $6\left(n_{1}=2 \%, n_{2}=26 \%, n_{3}=18 \%, n_{4}=7 \%, n_{5}=6 \%, n_{6}=41 \%\right)$ & $3,737.07$ & $3,670.45$ & $3,654.78$ & .702 & 21 \\
\hline
\end{tabular}

Notes. $B I C=$ Bayesian Information Criteria; $a B I C=$ Adjusted Bayesian Information Criteria; $A I C=$ Akaike Information Criteria. The chosen option is marked in bold.

Figure 1 displays the estimated growth curves for the different latent trajectories of life satisfaction across the transition to adulthood, and the results of the final Growth Mixture Model are presented in Table 3. The latent trajectories of life satisfaction were labelled lowstable (8\%), moderate-stable (41\%), high-stable (27\%), moderate-increasing (17\%), and high-decreasing (7\%). The low-stable trajectory had a low initial level of life satisfaction and this condition remained stable over time. The largest trajectory, moderate-stable, showed a moderate level of life satisfaction that remained stable over time. The high-stable trajectory showed a very high initial level of life satisfaction that remained stable over time. The moderate-increasing trajectory was characterised by a moderate initial level of life satisfaction that increased over time. The smallest trajectory, high-decreasing, was characterised by a high initial level of life satisfaction that showed a significant decrease over time. The results showed that most of the young adults -over three-quarters (76\%) followed a stable trajectory of life satisfaction, while the minority (24\%) followed a trajectory characterised by change. 
Figure 1. Life satisfaction trajectories

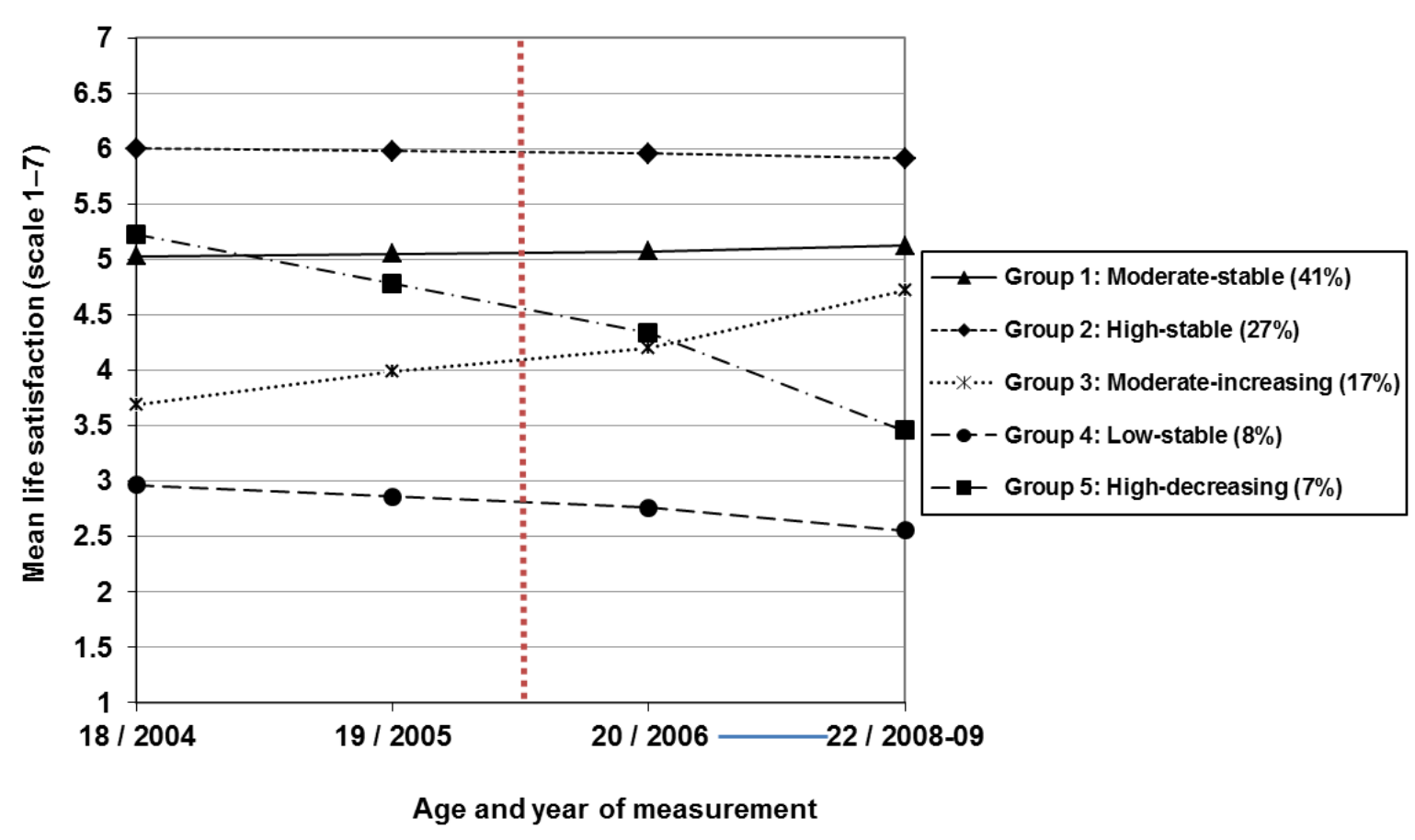

Note. The red dotted vertical line on the horizontal axis refers to the time of the transition to adulthood, i.e., to tertiary education and/or employment

Table 3. Estimation results of the final Growth Mixture Model with five latent classes (unstandardised estimates; standard errors in parentheses)

\begin{tabular}{|c|c|c|c|c|c|}
\hline & $\begin{array}{r}\text { Low-stable } \\
(N=30 ; 8 \%)\end{array}$ & $\begin{array}{l}\text { Moderate-stable } \\
(N=153 ; 41 \%)\end{array}$ & $\begin{array}{l}\text { High-stable } \\
(N=100 ; 27 \%)\end{array}$ & $\begin{array}{l}\text { Moderate-increasing } \\
(N=64 ; 17 \%)\end{array}$ & $\begin{array}{l}\text { High-decreasing } \\
(N=25 ; 7 \%)\end{array}$ \\
\hline \multicolumn{6}{|l|}{ Mean structure } \\
\hline Level & $2.96(0.19)^{* *}$ & $5.03(0.23)^{* *}$ & $6.00(0.13)^{* *}$ & $3.69(0.26)^{* *}$ & $5.22(0.30)^{* *}$ \\
\hline Linear change & $-0.10(0.10)$ & $0.02(0.04)$ & $-0.02(0.03)$ & $0.26(0.08)^{* *}$ & $-0.44(0.13)^{* *}$ \\
\hline
\end{tabular}

Notes. Variance is kept equal across the different latent groups.

** $p<.001$

As part of the second research question, the aim was to investigate whether the life satisfaction trajectories differed according to gender and family socio-economic status as background information, and parental financial support, living situation and life situation at the age of 22 (T4). The trajectories differed slightly according to family socio-economic status (SES) $\left[\chi^{2}(16, N=370)=30.03, p<.05\right]$ and life situation $\left[\chi^{2}=12, N=268=22.15, p<.05\right]$ However, post hoc tests did not identify specific statistically significant differences between the trajectories. Gender $\left[\chi^{2}(4, N=372)=5.30, p=.26\right.$, ns], parental financial support $\left[\chi^{2}(104, N=252)=\right.$ $100.19, p=.59, \mathrm{~ns}]$, and living situation $\left[\chi^{2}(20, N=\right.$ $369)=17.12, p=.65, \mathrm{~ns}]$ did not differ significantly between trajectories. 
The third research question investigated the relationship between achievement strategies and the identified life satisfaction trajectories in the transition to adulthood.

All effects and pairwise mean comparisons between the life satisfaction classes are summarised in Table 4. At age 19, the pairwise comparisons of means revealed initially rather high achievement approach strategies in two life satisfaction trajectories, namely, the high-stable and high-decreasing trajectories, and relatively high achievement avoidance strategies in the low-stable trajectory. Because a statistically significant result was found in both, post hoc comparisons using the Games-Howell test were computed and these indicated that the differences in achievement approach strategies, for example, between the high-decreasing, moderate-increasing, and lowstable trajectories, between the high-stable and moderate-increasing trajectories, and between the low-stable and moderate-stable trajectories were statistically significant $(p<.05)$. Moreover, statistically significant differences in achievement avoidance strategies were found, for example, between the high-stable, moderate-increasing and moderate-stable trajectories.

In terms of the achievement strategies at $\mathrm{T} 4$, at the age of 22, pairwise comparisons of means further revealed relatively high achievement approach strategies in the high-stable and moderate-stable life satisfaction trajectories, and rather high achievement avoidance strategies again in the low-stable trajectory. Post hoc comparisons using the Games-Howell test indicated that the differences in achievement approach strategies between the high-stable and moderate-increasing, between the high-stable and low-stable trajectories, and between the low-stable and moderate-stable trajectories were statistically significant $(p<.05)$. Moreover, a statistically significant difference in achievement avoidance strategies was found between the high-stable and low-stable trajectories.

As shown in Table 4, the highest mean levels in achievement avoidance strategies were present in the same trajectories over time, the low-stable and the moderate-increasing. However, for achievement approach strategies, the levels at age 19 were highest in the high-decreasing and the high-stable trajectories, but at age 22 , the second highest level was in the moderate-stable trajectory instead of the high-decreasing.

\section{The role of the financial situation}

The fourth aim of the study was to investigate how the subjective and objective financial situation of participants would be associated with the identified life satisfaction trajectories.

As noted above, all effects and pairwise mean comparisons between the life satisfaction classes are summarised in Table 4. The pairwise comparisons of means revealed rather high levels pertaining to individuals' subjective financial situation at the fourth measurement point in two life satisfaction trajectories, namely, the high-stable and moderate-stable trajectories. The post hoc comparison using the Games-Howell test indicated that the difference in individuals' subjective financial situation between the high-stable and moderate-increasing life satisfaction trajectories was statistically significant $(p<.05)$. Moreover, the differences in objective income level at Time 4 between the moderate-stable and moderateincreasing trajectories as well as between the moderate-stable and low-stable trajectories, were statistically significant. The extension of analyses from statistically non-significant correlations shown in Table 1, to the need for complex trajectory analyses, is also supported. 
Table 4. Mean differences in achievement strategies and self-reported objective and subjective financial situation between life satisfaction classes

\begin{tabular}{|c|c|c|c|c|c|c|c|c|c|c|c|c|c|}
\hline & \multicolumn{2}{|c|}{ Moderate-stable } & \multicolumn{2}{|c|}{ High-stable } & \multicolumn{2}{|c|}{ Moderate-increasing } & \multicolumn{2}{|c|}{ Low-stable } & \multicolumn{2}{|c|}{ High-decreasing } & \multirow[t]{2}{*}{$\boldsymbol{F}$} & \multirow[t]{2}{*}{$p$} & \multirow[t]{2}{*}{$\eta^{2}$} \\
\hline & $M$ & $S D$ & $M$ & $S D$ & $M$ & $S D$ & $M$ & $S D$ & $M$ & $S D$ & & & \\
\hline \multicolumn{14}{|c|}{ T2 Achievement strategies } \\
\hline Approach & $4.90_{\mathrm{ef}}$ & .77 & $5.56_{\text {cde }}$ & .68 & $4.45_{\mathrm{ac}}$ & .82 & $4.31_{\text {bdf }}$ & .96 & $5.07_{a b}$ & .96 & $F(4,348)=26.74$ & 0.000 & .24 \\
\hline Avoidance & $3.70_{c}$ & 1.25 & $3.04_{\mathrm{abc}}$ & 1.14 & $3.85_{a}$ & 1.25 & $4.33_{b}$ & 1.26 & 3.35 & 1.13 & $F(4,348)=8.55$ & 0.000 & .09 \\
\hline
\end{tabular}

T4 Achievement strategies

$\begin{array}{lllllllllllllll}\text { Approach } & 5.30_{\mathrm{c}} & .68 & 5.54_{\mathrm{ab}} & .89 & 4.99_{\mathrm{ac}} & .65 & 4.44_{\mathrm{bc}} & 1.01 & 4.98 & .98 & F(4,244)=8.60 & 0.000 & .12 \\ \text { Avoidance } & 3.21 & 1.11 & 2.77_{\mathrm{a}} & 1.28 & 3.40 & 1.15 & 4.03_{\mathrm{a}} & 1.32 & 3.07 & 1.41 & F(4,244)= & 4.64 & 0.001 & .07\end{array}$

T4 Financial situation

$\begin{array}{lllllllllllllll}\text { Subjective } & 3.36 & 1.11 & 3.56_{\mathrm{a}} & 1.15 & 2.87_{\mathrm{a}} & 1.06 & 2.76 & 1.25 & 2.80 & 1.61 & F(4,247)=3.90 & 0.004 & .06 & \\ \text { Objective } & 890_{\mathrm{ab}} & 498 & 882 & 628 & 645_{\mathrm{a}} & 318 & 662_{\mathrm{b}} & 241 & 882 & 353 & F(4,245)=2.51 & 0.042 & .04\end{array}$

Note. Class means in a row sharing the same subscripts are statistically different at the $p<.05$ level according to the Games-Howell test. 


\section{Discussion}

The first aim of this four-wave longitudinal study was to investigate the level and change in life satisfaction during the major transition to adulthood. The second aim was to examine whether there was evidence of differing life satisfaction trajectories during the longitudinal course of the transition to adulthood. Thirdly, we were interested in whether achievement strategies (i.e., agency) at ages 19 and 22 were associated with the identified life satisfaction trajectories. The final aim was to examine whether the financial situation of young adults was associated with these trajectories.

Based on results from similar studies, it was expected that most young adults would show high and stable life satisfaction (H1) (Salmela-Aro \& Tynkkynen, 2010). Because of the significant differences among individuals, the present study called for a person-oriented approach to studying individual development (Bergman et al., 2003; Bergman \& Andersson, 2010). A single growth trajectory would have oversimplified the heterogeneity of the changes in young adults' life satisfaction during the transition, as some individuals experience an increase and some a decrease in life satisfaction ( $\mathrm{H} 2)$, although most pass the stage with significant stability (Salmela-Aro \& Tynkkynen, 2010). In this study, it was possible to identify meaningful latent classes of individuals according to the initial levels and the longitudinal changes in their life satisfaction across the four measurement points. Adopting this multiple trajectories approach resulted in a model of five developmental trajectories. In regard to the role of financial factors, in accordance with our hypothesis $(\mathrm{H} 4)$, an association of positive life satisfaction trajectories with positive subjective and objective financial situations was identified to some degree in this transitional life course phase of young adulthood. The results also showed that the subjective perception of income is by far more important than the actual income, and this constitutes one of the key findings of our study. Evidently, the subjective perception is related to other personal and situational background factors, such as those relating to one's living situation which is a strong indicator of financial independence.

A multi-disciplinary framework fits well into the theme of young adulthood as a life course phase, with both life satisfaction and participants' financial situation in focus. The psychological life-span approach focuses on trajectories, continuity and developmental change, and often requires longitudinal studies (Cobb, 2010; Settersten, 2003). The sociological life course approach, on the other hand, focuses on the developmental implications of historical variation which indicate that human development and individual lives are shaped by a set of principles including individual agency, timing of events, linked lives and age-graded social pathways, as well as by the embeddedness of development in socio-historically changing contexts (Elder, 1998a; Settersten, 2003). The interaction of developmental psychology and the life-span approach with life course sociology has received little attention in previous research. Nevertheless, an increasing number of researchers are starting to integrate these perspectives in their research, for example in a recent study by Vuolo et al. (2012) examining how individuals with different psychological features react to the current recession.

As is often the case in life course research, this study is also concerned with the transition from one life stage to another (e.g., Settersten, 2003). Young adulthood is viewed as a staging ground for adulthood, when decisions affecting subsequent development are made (Crockett \& Crouter, 1995). In this study, the achievement strategies reflecting notions of agency were measured before the transition from upper secondary school to further education and/or employment. The strategies were closely linked to life satisfaction, both in regard to initial level and development, supporting our hypothesis (H3). Achievement approach strategies (having the belief of being able to succeed in challenging tasks), were at age 19 related to high life satisfaction trajectories (high-decreasing and high-stable). Similarly, achievement avoidance strategies were untypical for participants in the high-stable trajectory but related significantly to those in the low-stable trajectory. Interestingly, the moderate-increasing trajectory also showed a slightly higher level of achievement avoidance strategies. These results indicate that life satisfaction and achievement strategies go hand in hand, as individuals with a high level of achievement approach strategies tend to have a high level of life satisfaction, and on the contrary, a high level of achievement avoidance strategies was somewhat related to a low level of life satisfaction. 
Interestingly, the differences between classes remained similar from ages 19 to 22, although overall, the means of achievement avoidance strategies decreased within time in all of the classes. A closer look revealed that individuals in the moderate-increasing life satisfaction trajectory showed an increase in the mean level of achievement approach strategies, indicating that for this class achievement approach strategies and life satisfaction increase in parallel. However, the relation between agency - conceptualised as a high level of achievement approach strategies with a low level of achievement avoidance strategies - and life satisfaction is not entirely clear. In the moderatestable life satisfaction trajectory, even though achievement approach strategies increase, life satisfaction remains rather stable (although high). Furthermore, participants in the high-decreasing life satisfaction trajectory had a decreasing level of life satisfaction even though the level of their achievement approach strategies remained high and fairly stable. This indicates that although, in average, personal strivings and strategies have a significant effect on life satisfaction development, they cannot be entirely seen as protective factors against an evident decrease in life satisfaction.

Where these agentic attributions refer to the psychological dimension of this study, it is important to note that development does not solely occur in one particular type of context and individual developmental progress cannot be understood by merely focusing on the individual in isolation (Salmela-Aro \& Schoon, 2009). Youth sociologists must develop multi-disciplinary and international collaborations, and address the new research themes from the angle of a rapidly changing society with regard to events that have far-reaching implications for young adults (Furlong, 2011). For example, the economic downturn and changes in the labour market have led researchers and policymakers to believe that the transition to employment is highly problematic, and historically this can be seen as a repetitive and global phenomenon, at least in light of studies concerning Australia in the early 1980s and 1990s (Marks, 2005) and the United States in the late 2000s (Vuolo, Staff, \& Mortimer, 2012).

In this study, the link between participants' financial situation and life satisfaction is viewed within the framework of the important transitions that take place during the phase of young adulthood, when financial issues arise as a new concern in everyday life during the shift to independent living and working life. Research concerning young adults' overall financial wellbeing can be seen as a topic of much current societal debate pertaining to directing the critical eye of research at fundamental questions about students financing their studies, the role of parents in their children's financial situation, and youth in working life, to name but a few. Such research of socio-political significance, concerning both the economic and social structures of the society in addition to individual factors, is important.

Since the research data of our study was collected during times of economic difficulties in Finnish society in the late 2000s, this study also provides some insight into youth development and young adults' financial situations during such a time. Most individuals in different life course phases and transitions absorb greater economic tensions without long-term damage, but they survive societal and individual crises in different ways (Roberts, 2001). According to Finnish statistics (Wilska, 1999; Ylitalo, 2009), young adults' income and consumption levels decreased dramatically during the national recession of the early 1990s. At the same time, the status of young adults as consumers had not met the standards of other types of households: young adults under 30 years of age dropped their consumption levels by a fifth, while the decrease in other households was about $13 \%$.

Accordingly, our study aimed to provide useful information in face of the present, most recent economical downturn. The data sets' fourth measurement point was gathered during the peak of the present economic recession in 2008, which gives additional significance to the factor of participants' financial situation being featured in this particular data set. The present study links human development not only to the individual's life course, but also to the historical time and place, thus having a wider socio-historical context (Elder, 1998b; Settersten, 2003). In general, more life course studies that consider the social context of human development are needed, and large data sets allow developmental trajectory analyses within such a context (Settersten, 2003). The life course theory demonstrates that social contexts are more than behavioural settings - the social forces of 
time and place do shape individual pathways (Settersten, 2003).

The present study has the following main limitations that should be considered. First, one should be careful when generalising the findings to young adults of other countries. The study has been conducted in Finland, where young adults are able to profit from extensive financial support given by the state. It is also vital to bear in mind that even though our study includes data collected during an important educational transition, the data covered a short time period only. The validity of the overall link between financial situation and life satisfaction is therefore limited, even though this link has also been identified in numerous other studies. A further limitation of this issue is that in the selfreported scales of the questionnaire, the same reporter provided information on the different topics - life satisfaction, financial situation, and agency - and this may have influenced the observations of the associations between these factors. Additionally, only participants living in one city were given the chance to participate in this study and the retention rate could have been higher. Concerning the issue of attrition, we cannot be sure whether those who dropped out of the longitudinal research setting differed in their life satisfaction trajectories or their financial situation from those who participated until the end, although attrition was examined. Participants about whom information was missing for at least one of the measurement points were most likely to be male, which is also a clear limitation of our study. Additionally, the young adults being studied all had an upper secondary high school background which might explain the homogeneity of the life satisfaction trajectories across genders. Further studies are needed to examine the life satisfaction trajectories of young adults from other educational backgrounds and in other educational transitions.

Despite these limitations, the present study contributes to the understanding of human development by having longitudinally analysed the role of young adults' financial situation in relation to their life satisfaction. Methodologically and with respect to the data set used, our study's major advantage is its focus on developmental and life satisfaction trajectories pertaining to normative youth samples. The data of the study has been gathered both before and after the educational transition from upper secondary high school to further education and/or employment and is therefore of special interest as this transition often also encompasses other distinct changes in the transition to adulthood. Furthermore, using a multiple trajectories approach, this study has added value to existing research by providing a new multidisciplinary perspective on the topic of young adults' financial situation and changes in life satisfaction. The complexity of addressing participants' financial situation has been acknowledged in this study by examining it as a multi-dimensional construct, including both objective and subjective factors. What is objective, i.e., real and concrete, is the monetary income received monthly from various resources, but how each individual reflects upon it and estimates whether it is sufficient to support their personal consumer habits, is highly subjective. Additionally, because of greatly varying consumption habits, what one person considers to be a low income may be considered a fortune by someone else.

\section{Acknowledgements}

This study was supported by grants from the Jacobs Foundation and the Academy of Finland (nos. 134931,139168, and 213486). The first author has received personal funding for this study from the National Doctoral Programme of Psychology and the Finnish Cultural Foundation. The authors would like to thank Professor Terhi-Anna Wilska, Professor Raija-Leena Punamäki, and Dr Heta Tuominen-Soini for their helpful comments on previous versions of the manuscript. 


\section{References}

Bauer, B. J., \& Curran, P. J. (2003). Distributional assumptions of growth mixture models: implications for overextraction of latent trajectory classes. Psychological Methods, 8, 338-363. DOI: 10.1037/1082989X.8.3.338.

Bentler, P. M. (1990). Comparative fit indexes in structural models. Psychological Bulletin, 107, $238-246$. DOI: 10.1037/0033-2909.107.2.238.

Bergman, L. R., \& Andersson, H. (2010). The person and the variable in developmental psychology. Zeitschrift für Psychologie, Journal of Psychology, 218(3), 155-165. DOI: 10.1027/0044-3409/a000025

Bergman, L. R., Magnusson, D., \& El-Khouri, B. M. (2003). Studying individual development in an interindividual context: a person-oriented approach. London: Lawrence Erlbaum Associates.

Billari, F. C. (2001). The analysis of early life courses: complex descriptions of the transition to adulthood. Journal of Population Research, 18, 119-142. DOI: 10.1007/BF03031885.

Blossfield, H.-P., Klijzing, E., Mills, M., \& Kurz, K. (Eds.), (2005). Globalization, uncertainty and youth in society. London/New York, NY: Routledge.

Bowen, N. K., Lee, J. S., \& Weller B. (2007). Social environmental risk and protection: a typology with implications for practice in elementary schools. Children \& Schools, 29, 229-242. DOI: $10.1093 / \mathrm{cs} / 29.4 .229$.

Bronfenbrenner, U. (1979). The Ecology of Human Development: Experiments by Nature and Design. Cambridge, MA: Harvard University Press.

Buchmann, M., \& Kriesi, I. (2011). Transition to Adulthood in Europe. Annual Review of Sociology, 37, 481503. DOI: 10.1146/annurev-soc-081309-150212.

Cobb, N. (2010). Adolescence: Continuity, change, and diversity (7th ed.). Sunderland, MA: Sinauer Associates Inc. Publishers.

Conger, R. D., Conger, K. J., Matthews, L. S., \& Elder, G. H. (1999). Pathways of economic influence on adolescent adjustment. American Journal of Community Psychology, 27, 519-541. DOI: $10.1023 / A: 1022133228206$.

Costello, D. M., Swendsen, J., Rose, J. S., \& Dierker, L. C. (2008). Risk and protective factors associated with trajectories of depressed mood from adolescence to early adulthood. Journal of Counseling and Clinical Psychology, 76, 173-183. DOI: 0.1037/0022-006X.76.2.173.

Côté, J., \& Bynner, J. M. (2008). Changes in the transition to adulthood in the UK and Canada: The role of structure and agency in emerging adulthood. Journal of Youth Studies, 11, 251-268. DOI: $10.1080 / 13676260801946464$.

Cowan, P. A. (1991). Individual and family life transitions. A proposal for a new definition. In P. A. Cowan \& M. Hetherington (Eds.), Family transitions (pp. 4-30). Hillsdale, NJ: Lawrence Erlbaum Associates.

Crockett, L. J., Crouter, A. C. (1995). Pathways through adolescence: An overview. In L. J. Crockett (Eds.), Pathways through adolescence: Individual development in relation to social contexts (pp. 1-12). Mahwah, NJ: Lawrence Erlbaum Associates.

Cunnien, K. A., MartinRogers, N., \& Mortimer, J. T. (2009). Adolescent work experience and self-efficacy. International Journal of Sociology and Social Policy, 29(3/4), 164-175. DOI: 10.1108/01443330910947534.

Department for Communities and Local Government. (2011). Survey for English Housing Tables: Definitions and terms: Arrears - Tenancy. Available online at:

http://www.communities.gov.uk/housing/housingresearch/housingsurveys/surveyofenglishhousing/s ehlivetables/surveyenglish/224421/ (accessed 9 December 2012).

Diener, E., Emmons, R. A., Larsen, R. J., \& Griffin, S. (1985). The Satisfaction with Life Scale. Journal of Personality Assessment, 49, 71-75. DOI: 10.1207/s15327752jpa4901_13.

Diener, E., \& Seligman, M. E. P. (2002). Very happy people. Psychological Science, 31, 81-84. DOI: $10.1111 / 1467-9280.00415$.

Diener, E., \& Seligman, M. E. P. (2004). Beyond money. Toward an economy of well-being. Psychological Science in the Public Interest, 5(1), 1-31. DOI: 10.1111/j.0963-7214.2004.00501001.x.

Duncan, T. E., Duncas, S. C., \& Strycker, L. A. (2006). An introduction to latent variable growth curve modeling: concepts, issues, and applications (2nd ed.). Mahwah, NJ: Lawrence Erlbaum Associates.

Eccles, J. S., Midgley, C., Wigfield, A., Buchanan, C. M., Reuman, D., Flanagan, C., \& Iver D. M. (1993). Development during adolescence. The impact of stage-environment fit on young adolescents' experiences in schools and in families. American Psychologist, 48, 90-101. DOI: 10.1037/0003066X.48.2.90.

Elder, G. H., Jr. (1998a). The life course and human development. In W. Damon \& R. Lerner (Eds.), Theoretical models of human development. Handbook of child psychology (Vol. 1, pp. 939-991). Hoboken, NJ: John Wiley \& Sons, Inc.

Elder, G. H., Jr. (1998b). The life course as developmental theory. Child Development, 69, 1-12. DOI: 10.1111/j.1467-8624.1998.tb06128.x. 
Eronen, S. (2000). Achievement and social strategies and the cumulation of positive and negative experiences during young adulthood (Doctoral dissertation). Available online at: http://www.doria.fi/bitstream/handle/10024/3718/achievem.pdf?sequence $=2 \mathrm{w}$ (accessed 9 December 2012).

Eronen, S., Nurmi, J.-E., \& Salmela-Aro, K. (1997). Planning-oriented, avoidance and impulsive social strategies. A person-oriented approach. Journal of Research in Personality, 31, 34-57. DOI: 10.1006/jrpe.1997.2169.

Ervasti, H., \& Venetoklis, T. (2010). Unemployment and subjective well-being. Acta Sociologica, 53, 119-139. DOI: $10.1177 / 0001699310365624$.

Esping-Andersen, G. (1990). The three worlds of welfare capitalism. Princeton, NJ: Princeton University Press. Eurostat. (2009). Youth in Europe. A statistical portrait. Luxembourg: Publications Office of the European Union. Available online at: http://epp.eurostat.ec.europa.eu/cache/ITY OFFPUB/KS-78-09-920/EN/KS78-09-920-EN.PDF (accessed 15 January 2013).

Eurostat Statistics. (2010). 51 million young EU adults lived with their parent(s) in 2008. Statistics in focus, 50/2010. Population and social conditions. Marta Choroszewicz and Pascal Wolff. Available online at: http://epp.eurostat.ec.europa.eu/portal/page/portal/income social inclusion living conditions/intro duction (accessed 9 December 2012).

EUROSTUDENT. (2005-2008). Social and economic conditions of student life in Europe. National profile of Finland. Available online at: http://www.eurostudent.eu/results/profiles (accessed 9 December 2012).

Freund, A. M., \& Riediger, M. (2006). Goals as building blocks of personality and development in adulthood. In D. K. Mroczek, \& T. D. Little (Eds.), Handbook of Personality Development (pp. 353-372). Mahwah, $\mathrm{NJ}$ : Lawrence Erbaum Associates.

Furlong, A. (2011). Future agendas in the sociology of youth. Youth Studies Australia, 30, 54-59. Available online at: $\underline{\text { http://search.informit.com.au/documentSummary;dn=328885871102374;res=IELHSS }}$ (accessed 9 December 2012).

Furlong, A., \& Cartmel, F. (2007). Young people and social change. New perspectives. Berkshire: Open University Press.

Giddens, A. (1991). Modernity and Self-Identity. Self and Society in the Late Modern Age. Oxford: Blackwell Publishers.

Graber, J. A., \& Brooks-Gunn, J. (1996). Transitions and turning points: Navigating the passage from childhood through adolescence. Developmental Psychology, 32, 768-776. DOI : 10.1037/00121649.32.4.768.

Haase, C. M., Heckhausen, J., \& Silbereisen, R. K. (2012). The interplay of occupational motivation and wellbeing during the transition from university to work. Developmental Psychology, 48, 1739-1751. DOI: $10.1037 / \mathrm{a} 0026641$.

Häkkinen, I. (2004). Working while enrolled in a university: does it pay? Working Paper, 1, Uppsala University, Department of Economics. DOI: 10.1016/j.labeco.2004.10.003

Häkkinen, I., \& Uusitalo, R. (2003). Working Paper Series, 8, Uppsala University, Department of Economics. Available online at: http://ideas.repec.org/p/hhs/uunewp/2003 008.html\#biblio (accessed 9 December 2012).

Heckhausen, J., Wrosch, C., \& Schulz (2010). A motivational theory of life-span development. Psychological Review, 117, 32-60. DOI: 10.1037/a0017668.

Hendry, L. B., \& Kloep, M. (2007a). Redressing the emperor! - A rejoinder to Arnett. Child Development Perspectives, 1(2), 83-85. DOI: 10.1111/j.1750-8606.2007.00019.x.

Hendry, L. B., \& Kloep, M. (2007b). Conceptualizing emerging adulthood: Inspecting the emperor's new clothes? Child Development Perspectives, 1, 74-79. DOI: 10.1111/j.1750-8606.2007.00017.x.

$\mathrm{Hu}$, L., \& Bentler, P. M. (1998). Fit indices in covariance structure modeling: sensitivity to underparameterized model misspecification. Psychological Methods, 3, 424-453. DOI : 10.1037/1082-989X.3.4.424.

Johnson, M. K., \& Benson J. (2012). The implications of family context for the transition to adulthood. In A. Booth, S. L. Brown, N. S. Landale, W. D. Manning, \& S. M. McHale (Eds.), Early Adulthood in a Family Context. National Symposium on Family Issues, 2, 87-103. New York, NY: Springer. Available online at: http://www.springerlink.com/content/978-1-4614-1436-0\#section=1001609\&page=1\&locus=94 (accessed 9 December 2012).

Jorgensen, B. S., Jamieson, R. D., \& Martin, J. F. (2010). Income, sense of community and subjective wellbeing: Combining economic and psychological variables. Journal of Economic Psychology, 31, 612-623. DOI: $10.1016 /$ j.joep.2010.04.002

Lee, J. C., \& Mortimer, J. T. (2009). Family socialization, economic self-efficacy, and the attainment of financial independence in early adulthood. Longitudinal and Life Course Studies, 1, 45-62. Available online at: http://www.ncbi.nlm.nih.gov/pubmed/22025928 (accessed 9 December 2012).

Lucas, R. E., \& Donnellan, M. B. (2007). How stable is happiness? Using the STARTS Model to estimate the stability of life satisfaction. Journal of Research in Personality, 41, 1091-1098.

DOI: 10.1016/j.jrp.2006.11.005. 
Luyckx, K., De Witte, H., \& Goossens, L. (2011). Perceived instability in emerging adulthood: The protective role of identity capital. Journal of Applied Developmental Psychology, 32, 137-145. DOI: 10.1016/j.appdev.2011.02.002.

Lüdtke, O., Roberts, B. W., Trautwein, U., \& Nagy, G. (2011). A random walk down university avenue: Life paths, life events, and personality trait change at the transition to university life. Journal of Personality and Social Psychology, 101, 620-637. DOI : 10.1037/a0023743.

Marks, G. N. (2005). Issues in the school-to-work transition: Evidence from the longitudinal surveys of Australian youth. Journal of Sociology, 41, 363-385. DOI : 10.1177/1440783305058470.

Marsh, H. W., Lüdtke, O., Trautwein, U., \& Morin, A. J. S. (2009). Classical latent profile analysis of academic self-concept dimensions: synergy of person- and variable-centered approaches to theoretical models of self-concept. Structural Equation Modeling, 16, 191-225. DOI: 10.1080/10705510902751010.

Ministry of Education and Culture. (2005). OECD thematic review of tertiary education; Country Background Report for Finland. Publications of the Ministry of Education, Finland, 38. Ministry of Education, Department for Education and Social Policy, Helsinki. Available online at: http://www.minedu.fi/OPM/Julkaisut/2005/oecd thematic review of tertiary education country b ackground r?lang=\&extra locale=en (accessed 9 December 2012).

Modell, J., Furstenberg, F. F., \& Hershberg, T. (1976). Social change and transitions to adulthood in historical perspective. Journal of Family History, 38, 7-32. DOI: 10.1177/036319907600100103.

Mortimer, J. T. (2012). Transition to adulthood, parental support, and early adult well-being: Recent findings from the youth development study. In A. Booth, S. L. Brown, N. S. Landale, W. D. Manning, \& S. M. McHale, (Eds.), Early Adulthood in a Family Context. National Symposium on Family Issues, 2, 27-34. New York, NY: Springer. DOI: 10.1007/978-1-4614-1436-0_2.

Mortimer, J. T., \& Larson, R. W. (2002). Macrostructural trends and the reshaping of adolescence. In Mortimer, J. T., \& R. W. Larson (Eds.), The changing adolescent experience. Societal trends and the transition to adulthood (pp. 1-17). Cambridge: Cambridge University Press.

Muthén, B. O. (2001). Second-generation structural equation modeling with a combination of categorical and continuous latent variables. New opportunities for latent class/latent growth modeling. In L. M. Collins, \& A. Sayer (Eds.), New methods for theanalysis of change (pp. 291-322). Washington, DC: APA.

Muthén, B. O. (2003). Statistical and substantive checking in growth mixture modeling: comment on Bauer and Curran. Psychological Methods, 8, 369-377. Available online at: http://psycnet.apa.org/?\&fa=main.doiLanding\&doi=10.1037/1082-989X.8.3.369 (accessed 9 December 2012).

Muthén, B. O. (2004). Latent variable analysis: growth mixture modeling and related techniques for longitudinal data. In D. Kaplan (Ed.), Handbook of quantitative methodology for the social sciences (pp. 345-368). Newbury Park: Sage.

Muthén, L. K., \& Muthén, B. O. (1998-2007). Mplus user's guide.

Muthén, B. O., \& Muthén, L. K. (2000). Integrating person-centered and variable-centered analyses: Growth mixture modeling with latent trajectory classes. Alcoholism: Clinical and Experimental Research, 24, 882-891. Available online at: http://pages.gseis.ucla.edu/faculty/muthen/articles/Article 085.pdf (accessed 9 December 2012).

Muthén, B. O., \& Shedden, K. (1999). Finite mixture modeling with mixture outcomes using the EM algorithm. Biometrics, 55, 463-469. Available online at: http://pages.gseis.ucla.edu/faculty/muthen/articles/Article 078.pdf (accessed 9 December 2012).

Nagin, D. S. (1999). Analyzing developmental trajectories: A semiparametric, group-based approach. Psychological Methods, 4, 139-157. DOI: 10.1037/1082-989X.4.2.139.

Nagin, D. S., \& Land, K. C. (1993). Age, criminal careers, and population heterogeneity: Specification and estimation of a nonparametric, mixed Poisson model. Criminology, 31, 327-362. DOI: 10.1111/j.17459125.1993.tb01133.x

Nagin, D. S., \& Tremblay, R. E. (1999). Trajectories of boys' physical aggression, opposition, and hyperactivity on the path to physically violent and nonviolent juvenile delinquency. Child Development, 70, 11811196. Available online at: http://www.gripinfo.ca/grip/public/www/doc/articles/Nagin 1999 id 199.pdf (accessed 9 December 2012).

Noble, S. M., Haytko, D. L., \& Phillips, J. (2008). What drives college-age Generation Y consumers? Journal of Business Research, 62, 617-628. DOI: 10.1016/j.jbusres.2008.01.020.

Nurmi, J.-E. (2004). Socialization and self-development: Chaneling, selection, adjustment, and reflection. In Lerner, R., \& Steinberg, L. (Eds.), Handbook of Adolescent Psychology (85-124). New York: Wiley.

Nurmi, J.-E., Aunola, K., Salmela-Aro, K., \& Lindroos, M. (2003). The role of success expectation and taskavoidance in academic performance and satisfaction: Three studies on antecedents, consequences and correlates. Contemporary Educational Psychology, 28, 59-90. DOI: 10.1016/S0361476X(02)00014-0. 
Nurmi, J.-E., Salmela-Aro, K., \& Haavisto, T. (1995). The Strategy and Attribution Questionnaire: psychometric properties. European Journal of Psychological Assessment, 11, 108-121. DOI : 10.1027/1015-5759.11.2.108.

Official Statistics of Finland (OSF). (2011). Entrance to education [e-publication].Helsinki: Statistics Finland. Available online at: http://www.stat.fi/til/khak/2011/khak 2011 2012-12-13 tie 001 en.html (accessed 20 January 2013).

Orr, D., Gwosć, C., \& Netz, N. (2011). Social and economic conditions of student life in Europe. Synopsis of indicators. Final report. Eurostudent IV (2008-2011). Bielefeld: W. Bertelsmann Verlag.

Perren, S., Keller, R., Passardi, M., \& Scholz, U. (2010). Well-being curves across transitions. The development of a retrospective measure. Swiss Journal of Psychology, 69, 15-29. DOI: 10.1024/1421-0185.a000003.

Powers, S. I., Hauser, S. T., \& Kilner, L. A. (1989). Adolescent mental health. American Psychologist, 44, 200208. DOI: 10.1037/0003-066X.44.2.200.

Räikkönen, E., Kokko, K., Chen, M., \& Pulkkinen, L. (2012). Patterns of adult roles, their antecedents and psychosocial wellbeing correlates among Finns born in 1959. Longitudinal and Life Course Studies, 3, 211-227.

Ranta, M., Punamäki, R.-L., Tolvanen, A., \& Salmela-Aro, K. (2012). The role of financial resources and agency in success and satisfaction regarding developmental tasks in early adulthood. In S. L. Blair (Ed.), Economic Stress and the Family (Contemporary Perspectives in Family Research, Vol. 6, pp. 187-233). Emerald Group Publishing Limited. DOI: 10.1108/S1530-3535(2012)0000006011.

Rindfuss, R. R. (1991). The young adult years: diversity, structural change and fertility. Demography, 28, 493512. DOI: $10.2307 / 2061419$.

Roberts, K. (2001). Unemployment without social exclusion: evidence from young people in Eastern Europe. International Journal of Sociology and Social Policy, 21, 118-144. DOI: 10.1108/01443330110789466.

Roberts, K., Osadchaya, G. I., Dsuzev, K. V., Gorodyanenko, V. G., \& Tholen, J. (2003). Economic conditions, and the family and housing transitions of young adults in Russia and Ukraine. Journal of Youth Studies, 6, 71-88. DOI: 10.1080/1367626032000068172.

Salmela-Aro, K. (2009). Personal Goals and Well-Being during Critical Life Transitions: The Four C'sChanneling, Choice, Co-Agency and Compensation. Advances in Life Course Research, 14, 63-73. DOI: 10.1016/j.alcr.2009.03.003.

Salmela-Aro, K., Ek, E., Taanila, A., \& Chen, M. (2012). Role configurations in young adulthood, antecedents, and later well-being among Finns born in 1966. Longitudinal and Life Course Studies, 3, $228-242$.

Salmela-Aro, K., \& Little, B. R. (2007). Mine, yours, ours and others: Relational aspects of Project Pursuit. In B. R. Little, K. Salmela-Aro, \& S. D. Phillips (Eds.), Personal Project Pursuit. Goals, Action, and Human Flourishing (pp. 199-220). Mahwah, NJ: Lawrence Erlbaum Associates.

Salmela-Aro, K., \& Schoon, I. (2009). Youth development in Europe. Transitions and identities. European Psychologist, 14, 372-375. DOI : 10.1027/1016-9040.14.4.372.

Salmela-Aro, K., \& Tuominen-Soini, H. (2010). Adolescents' life satisfaction during the transition to postcomprehensive education: antecedents and consequences. Journal of Happiness Studies, 11, 683-701. DOI: $10.1007 / s 10902-009-9156-3$.

Salmela-Aro, K., \& Tynkkynen, L. (2010). Trajectories of life satisfaction across the transition to postcomprehensive education: do adolescents follow different pathways? Journal of Youth and Adolescence, 39, 870-881. DOI: 10.1007/s10964-009-9464-2.

Schulenberg, J., Sameroff, A. J., \& Cicchetti, D. (2004). The transition to adulthood as a critical juncture in the course of psychopathology and mental health. Development and Psychopathology, 16, 799-806. DOI: $10.1017 /$ S0954579404040015.

Settersten, R. A., Jr. (Ed.). (2003). Invitation to the life course: toward new understandings of later life. New York, NY: Baywood Publishing Company, Inc.

Shim, S., Xiao, J. J., Barber, B. L., \& Lyons, A. C. (2009). Pathways to life success: a conceptual model of financial well-being for young adults. Journal of Applied Developmental Psychology, 30, 708-723. DOI: 10.1016/j.appdev.2009.02.003.

Statistics Finland. (1989). Classification of Socioeconomic Status. Handbooks 17.

Statistics Finland. (2009). Education Statistics. Available online at: http://www.stat.fi/til/khak/2008/khak 2008 2009-12-09 tie 001 en.htmlh (accessed 9 December 2012).

Statistics Finland. (2010a). Education 2009. Available online at: http://tilastokeskus.fi/til/lop/2009/lop 2009 2010-06-11 tie 001 en.html (accessed 9 December 2012).

Statistics Finland. (2010b). Education 2010. Available online at: http://www.stat.fi/til/sijk/2008/sijk 2008 2010-03-23 tie 001 en.html (accessed 9 December 2012).

Statistics Finland. (2011a). Education 2011. Available online at: http://www.stat.fi/til/opty/2009/opty 2009 2011-03-15 tie 001 en.html (accessed 9 December 2012). 
Statistics Finland. (2011b). Household's reference person. Available online at: http://www.stat.fi/meta/kas/kotital viite en.html (accessed 9 December 2012).

Steiger, J. H. (1990). Structural model evaluation and modification: an interval estimation approach. Multivariate Behavioral Research, 25, 173-180. Available online at: http://www.statpower.net/Steiger\%20Biblio/Steiger90b.pdf (accessed 23 January 2013).

Stein, C. H., Abraham, K. M., Bonar, E. E., Leith, J. E., Kraus, S. W., Hamill, A. C., Gumber S., Hoffmann, E., \& Fogo, W. R. (2011). Family ties in tough times: How young adults and their parents view the U.S. economic crisis. Journal of Family Psychology, 25, 449-454. DOI: 10.1037/a0023697.

Vuolo, M., Staff, J., \& Mortimer, J. T. (2012). Weathering the Great Recession: Psychological and behavioral trajectories in the transition from school to work. Developmental Psychology, 48, 1759-1773. DOI: 10.1037/a9926047.

West, P., Sweeting, H., Young, R., \& Robins, M. (2006). A material paradox: Socioeconomic status, young people's disposable income and consumer culture. Journal of Youth Studies, 9(4), 437-462. Available online at: http://www.tandfonline.com/doi/full/10.1080/13676260600805739 (accessed 9 December 2012).

Wilska, T. A. (1999). Survival with dignity? The consumption of young adults during economic depression: a comparative study of Finland and Britain (1990-1994). Publications of the Turku School of Economics and Business Administration, Series A-3 (1999).

Ylitalo, M. (2009). Hyvinvointikatsaus 1/2009 [Well-being review]. Tilastokeskus (Statistics Finland). Available online at: http://www.stat.fi/artikkelit/2009/art 2009-03-16 003.html?s=0 (accessed 23 January 2013). 